\title{
Advanced Maternal Age and the Risk of Major Congenital Anomalies
}

\author{
Katherine R. Goetzinger, MD, MSCl ${ }^{1}$ Anthony L. Shanks, $\mathrm{MD}^{2}$ Anthony O. Odibo, MD, MSCE ${ }^{3}$ \\ George A. Macones, MD, MSCE ${ }^{4}$ Alison G. Cahill, MD, $\mathrm{MSCl}^{4}$
}

${ }^{1}$ Department of Obstetrics, Gynecology and Reproductive Sciences,
University of Maryland, Baltimore, Maryland
${ }^{2}$ Department of Obstetrics and Gynecology, Indiana University School
of Medicine, Indianapolis, Indiana
${ }^{3}$ Department of Obstetrics and Gynecology, University of South
Florida, Tampa, Florida
${ }^{4}$ Department of Obstetrics and Gynecology, Washington University,
St. Louis, Missouri

Am J Perinatol

\begin{abstract}
Keywords

- advanced maternal age

- aneuploidy

- congenital anomalies

- fetal structural malformation

Objective This study aims to determine if advanced maternal age (AMA) is a risk factor for major congenital anomalies, in the absence of aneuploidy.

Study Design Retrospective cohort study of all patients with a singleton gestation presenting for second trimester anatomic survey over a 19-year study period. Aneuploid fetuses were excluded. Study groups were defined by maternal age $\leq 34$ and $\geq 35$ years. The primary outcome was the presence of one or more major anomalies diagnosed at the second trimester ultrasound. Univariable and multivariable logistic regression analyses were used to estimate the risk of major anomalies in AMA patients. Results Of 76,156 euploid fetuses, $2.4 \%(n=1,804)$ were diagnosed with a major anomaly. There was a significant decrease in the incidence of major fetal anomalies with increasing maternal age until the threshold of age $35(p<0.001)$. Being AMA was significantly associated with an overall decreased risk for major fetal anomalies (adjusted odds ratio: $0.59,95 \%$ confidence interval: $0.52-0.66$ ). The subgroup analysis demonstrated similar results for women $\geq 40$ years of age.

Conclusion AMA is associated with an overall decreased risk for major anomalies. These findings may suggest that the "all or nothing" phenomenon plays a more robust role in embryonic development with advancing oocyte age, with anatomically normal fetuses being more likely to survive.
\end{abstract}

Address for correspondence Katherine R. Goetzinger, MD, MSCI, Department of Obstetrics, Gynecology and Reproductive Sciences, University of Maryland School of Medicine, 22 South Greene Street, Room N6W104F, Baltimore, MD 21201 (e-mail: kgoetzinger@fpi.umaryland.edu).
Over the past 20 years, there has been an increasing trend in the number of pregnancies achieved by women of advanced maternal age (AMA). ${ }^{1}$ These women are at an increased risk of multiple pregnancy complications such as spontaneous abortion, preeclampsia, gestational diabetes, fetal growth restriction, and stillbirth. ${ }^{2-6}$ In addition, AMA is a well-established risk factor for chromosomal abnormalities, such as trisomy 21, due to errors in meiotic nondisjunction with advancing oocyte age. Despite these known pregnancy risks, there exists limited data evaluating the relationship between being AMA and the incidence of congenital anomalies in the absence of aneuploidy.

Prior studies on this topic have generated conflicting results. ${ }^{2,7-12}$ In a large prospective cohort study, Hollier et al demonstrated an additional 1\% age-related risk of nonchromosomal abnormalities in women age 35 or older. ${ }^{7}$ Conversely, Baird et al found no association between the incidence of congenital malformations and advancing maternal age. ${ }^{8}$ In fact, more recent studies suggest that young received

April 7, 2016

accepted after revision

June 8,2016
Copyright $\odot$ by Thieme Medical

Publishers, Inc., 333 Seventh Avenue, New York, NY 10001, USA. Tel: +1(212) 584-4662.
DOI http://dx.doi.org/ $10.1055 / \mathrm{s}-0036-1585410$. ISSN $0735-1631$.

This is the author's manuscript of the article published in final edited form as: Goetzinger, K. R., Shanks, A. L., Odibo, A. O., Macones, G. A., \& Cahill, A. G. (2016). Advanced Maternal Age and the Risk of Major Congenital Anomalies. American Journal of Perinatology. https://doi.org/10.1055/s-0036-1585410 
maternal age actually may be a stronger risk factor for certain congenital anomalies compared with advanced age. ${ }^{12-14}$ Limitations of many of these studies include their reliance on birth certificate data, which is often incomplete and subject to ascertainment bias. Furthermore, the majority of available studies have been unable to capture information on stillbirths and terminations, thereby likely missing a significant proportion of anomalous fetuses. Finally, existing studies largely have been unable to account for the multiple confounders that may independently increase the risk for congenital anomalies.

Given this limited and conflicting data, the objective of this study was to estimate the risk of major congenital anomalies in women of advanced maternal age in the absence of aneuploidy using a large ultrasound and perinatal database. This information will be useful in counseling women about their risk of having a structurally normal fetus, especially in the setting of normal aneuploidy screening.

\section{Materials and Methods}

This was a retrospective cohort study of consecutive patients with a singleton gestation presenting to the Division of Ultrasound and Genetics, Washington University in St. Louis for second-trimester anatomic survey from 1990 to 2009. Institutional review board approval from our institution was obtained. All anatomic surveys performed between 16 and 24 weeks gestation were included. If all sonographic views could not be completed during the initial examination, patients were asked to return in 2 to 4 weeks' time for completion of the anatomic survey. Multiple gestations and pregnancies with chromosomal abnormalities were excluded. Chromosomal abnormalities were identified through prenatal diagnosis or postnatal testing, when examination findings were suspicious. Maternal demographic information, obstetrical history, and medical history are routinely obtained through patient questionnaire at each encounter and entered into a comprehensive database. All suspected fetal anomalies and sonographic markers of aneuploidy are also entered into this database at the time of the examination. Ultrasound examinations are performed by dedicated obstetrical sonographers and are interpreted by maternal-fetal medicine specialists. Pregnancy and neonatal outcomes are prospectively collected by a dedicated nurse outcome coordinator. All sonographically suspected fetal anomalies are confirmed after birth. In addition, anomalies diagnosed after birth are also collected and entered into the database by the nurse outcome coordinator. Neonatal information is obtained by medical record abstraction as well as questionnaire or phone call to the patient or referring obstetric provider.

Study groups were defined by maternal age $\leq 34$ years and maternal age $\geq 35$ years at the time of delivery. ${ }^{15}$ The primary outcome of the study was the presence of one or more major anomalies diagnosed at the time of second trimester ultrasound. This outcome was chosen to capture all anomalous pregnancies, including those that may result in stillbirth or termination. An anomaly was defined as a defect in the structure of an organ which resulted from a specific primary abnormality of organogenesis. ${ }^{16}$ Examples of major anomalies include congenital heart defects, neural tube defects, gastroschisis, and omphalocele. Markers of aneuploidy, such as thickened nuchal fold or absent/hypoplastic nasal bone, were not considered to be major congenital anomalies. Secondary outcomes included the distribution of individual major congenital anomalies by organ system, including central nervous system (CNS), cardiac, renal, thoracic, head and neck, musculoskeletal, gastrointestinal, and abdominal wall defects.

Baseline maternal characteristics as well as the incidence of the primary and secondary outcomes were compared between the study groups using chi-square and Fisher exact tests for categorical variables and Student $t$-test for continuous variables. Normality of distribution was assessed using the Kolmogorov-Smirnov test. The distribution of anomaly type by organ system was also compared between the study groups. A Cochran-Armitage test for trend was used to evaluate for any significant pattern in the incidence of major fetal malformations across maternal age categories. Univariable analysis was used to estimate the relative risks (RR) and 95\% confidence intervals (CIs) of the association between the AMA and major congenital malformations. Multivariable logistic regression analysis then was used to estimate the adjusted odds ratio (aOR) for the primary and secondary outcomes, controlling for confounders identified both historically and through univariable analysis. Separate logistic regression models were run for each organ system, and nonsignificant variables were removed in a backward stepwise fashion. A subgroup analysis was also performed comparing the risk of major congenital anomalies in women age $\geq 40$ years and women $\leq 39$ years. The $p$ values $<0.05$ were considered statistically significant. All statistical analysis was performed using STATA 12.0 special edition software (StataCorp, College Station, TX).

\section{Results}

A total of 76,453 patients with singleton gestations were included in our perinatal database over the study period. After excluding 297 (0.4\%) patients with fetal chromosomal abnormalities, 76,156 patients comprised our final study cohort. Of these patients, 20,803 (27.3\%) were AMA. On average, patients who were AMA were of higher gravidity and parity and had a lower body mass index (BMI) compared with patients who were not AMA. Patients who were AMA also were more likely to be Caucasian, report a history of alcohol use during pregnancy and have a history of chronic hypertension and/or diabetes (both preexisting and gestational) (-Table 1). Finally, patients who were AMA were significantly more likely to present at an earlier gestational age for second trimester anatomic survey compared with patients $\leq 34$ years old $(18.7 \pm 1.6$ weeks vs. $19.4 \pm 1.7$ weeks; $p<0.001$ ).

The overall incidence of major fetal anomalies in our cohort was $2.4 \%(n=1,804)$. There was a statistically significant decrease in the incidence of all major congenital anomalies with increasing maternal age until the threshold of age 35 $(p<0.001)$. This incidence ranged from $3.2 \%$ in women $<20$ years old to $1.7 \%$ in women $>35$ years old ( - Fig. $\mathbf{1}$ ). - Fig. 2 demonstrates the distribution of the major anomalies by organ 
Table 1 Maternal demographics and pregnancy characteristics compared between patients $\geq 35$ y (AMA) and $\leq 34$ y

\begin{tabular}{|l|l|l|l|}
\hline Variable & $\begin{array}{l}\text { AMA } \\
\boldsymbol{n}=\mathbf{2 0 , 8 0 3}\end{array}$ & $\begin{array}{l}\text { Age } \leq \mathbf{3 4} \\
\boldsymbol{n}=\mathbf{5 5 , 3 5 3}\end{array}$ & $\boldsymbol{p}$ Value \\
\hline $\begin{array}{l}\text { Mean Maternal } \\
\text { Age }(\mathrm{y})^{\mathrm{a}}\end{array}$ & $37.6 \pm 2.3$ & $26.9 \pm 4.8$ & $<0.001$ \\
\hline Mean gravidity $^{\mathrm{a}}$ & $3.3 \pm 1.8$ & $2.4 \pm 1.5$ & $<0.001$ \\
\hline Mean parity $^{\mathrm{a}}$ & $1.4 \pm 1.3$ & $0.9 \pm 1.1$ & $<0.001$ \\
\hline Mean BMl $\left(\mathrm{kg} / \mathrm{m}^{2}\right)^{\mathrm{a}}$ & $26.8 \pm 6.4$ & $27.1 \pm 6.7$ & $<0.001$ \\
\hline Caucasian race $^{\text {African American }}$ & $70.2 \%$ & $54.8 \%$ & $<0.001$ \\
\hline race & $12.6 \%$ & $29.9 \%$ & $<0.001$ \\
\hline Tobacco exposure & $11.5 \%$ & $11.9 \%$ & 0.13 \\
\hline Alcohol exposure & $26.8 \%$ & $14.7 \%$ & $<0.001$ \\
\hline $\begin{array}{l}\text { Maternal chronic } \\
\text { hypertension }\end{array}$ & $3.9 \%$ & $1.9 \%$ & $<0.001$ \\
\hline Maternal diabetes & $8.3 \%$ & $5.3 \%$ & $<0.001$ \\
\hline Preeclampsia & $7.0 \%$ & $8.4 \%$ & $<0.001$ \\
\hline
\end{tabular}

Abbreviations: AMA, advanced maternal age; BMI, body mass index. ${ }^{a}$ Data reported as mean \pm standard deviation.

system compared between the study groups. CNS, cardiac and renal anomalies were the most common organ system malformations in both the AMA patients and patients $\leq 34$ years old. Abdominal wall defects (both gastroschisis and omphalocele) were observed more frequently in patients $\leq 34$ years old; whereas, head and neck malformations were observed more frequently in AMA patients. The other anomaly distributions were similar between the study groups.

Overall, AMA was significantly associated with a $40 \%$ reduction in the risk of having one or more major fetal congenital anomalies compared with women $\leq 34$ years old, after controlling for race, diabetes, and alcohol use during pregnancy (1.7\% vs. $2.6 \%$; aOR: $0.59,95 \% \mathrm{CI}$ : 0.52-0.66). On evaluation of major anomalies by organ system, AMA patients

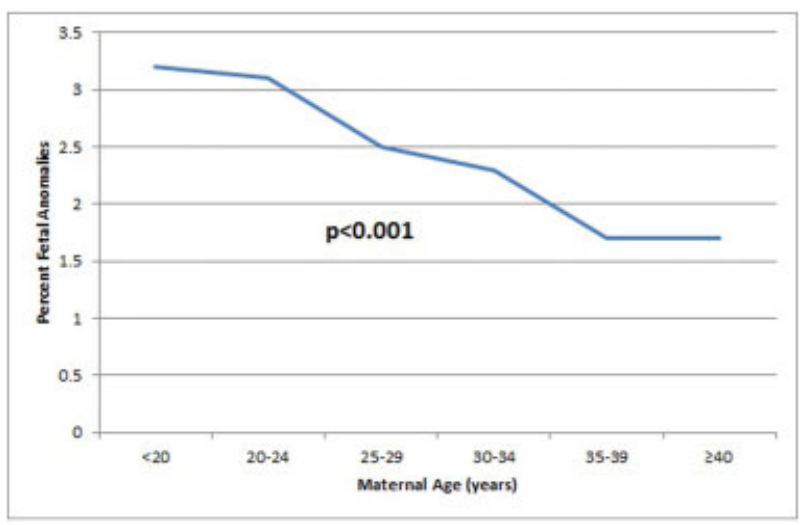

Fig. 1 Incidence of major congenital anomalies by maternal age. The $x$-axis represents maternal age in 5 -year age increments. The $y$-axis represents the incidence of major congenital anomalies in absolute percentages. The $p$ value obtained from Cochran-Armitage test for trend.

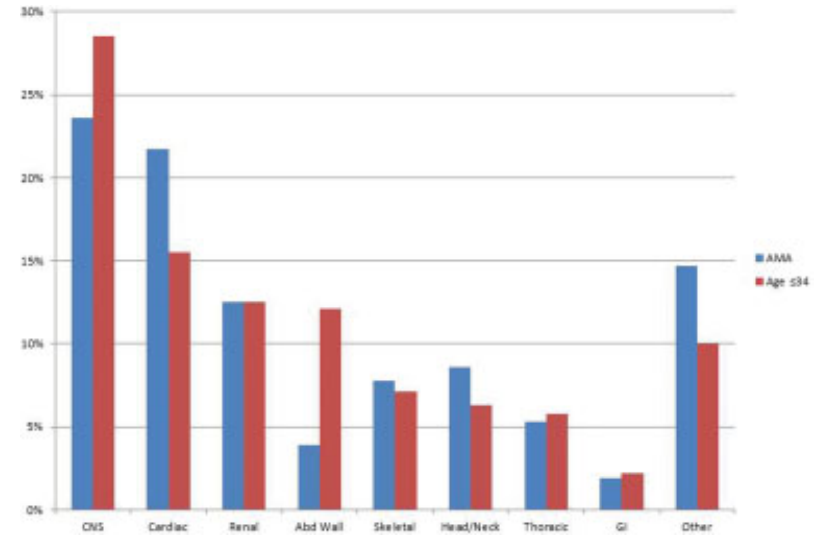

Fig. 2 Distribution of anomalies by organ system in both the AMA group and age $\leq 34$ referent group. AMA, advanced maternal age.

were also less likely to be diagnosed with a fetal CNS, renal, thoracic or abdominal wall defect after controlling for confounders. The incidence of cardiac, head/neck, gastrointestinal, and skeletal anomalies was similar between the study groups (-Table 2). Given the small absolute number of anomalies in the organ system categories of head/neck, gastrointestinal, and musculoskeletal, adjusted analysis could not reliably be performed.

Similar results were obtained in a subgroup analysis of women $\geq 40$ years old $(n=4,065)$. Women who were $\geq 40$ were also at a significantly decreased risk of having any major fetal anomaly (aOR: 0.70, 95\% CI: 0.54-0.90) after controlling for alcohol use, diabetes, race, and BMI. In addition, women who were $\geq 40$ were also less likely to be diagnosed with a fetal CNS (aOR: $0.49,95 \%$ CI: $0.29-0.84$ ) or renal (RR: $0.16,95 \% \mathrm{CI}$ : 0.04-0.64) anomaly compared with women $\leq 39$ years old. Similar to the primary analysis, the incidence of cardiac defects did not differ between the two study groups (-Table 3 ).

To account for the 19 year study period and associated improvements in ultrasound diagnosis and technology over time, we divided the study period into 5-year quartiles and evaluated the incidence of major anomalies diagnosed in each quartile. Each quartile demonstrated a consistent incidence of anomalies of approximately $2 \%$, indicating the stability of sonographic diagnosis over time at our institution.

\section{Comment}

Our study demonstrates that AMA is associated with an overall decreased risk for major congenital malformations in the absence of aneuploidy. This decrease in risk appears to be primarily driven by a decreased incidence of CNS, renal and abdominal wall defects, and contrasted by a similar incidence of cardiac defects. In addition, comparable results were observed using varying thresholds to define AMA, thus strengthening the validity of our findings.

The limited number of studies that do exist on this topic have generated conflicting results. In 2000, Hollier et al published a large prospective cohort study of 102,728 singleton pregnancies, both liveborn and stillborn, delivered over a 7-year period at a tertiary care center. When evaluating the 
AMA and the Risk of Major Congenital Anomalies Goetzinger et al.

Table 2 Association between AMA $\geq 35$ y and major congenital anomalies by organ system

\begin{tabular}{|c|c|c|c|c|c|}
\hline Variable & $\begin{array}{l}\text { AMA } \\
n=20,803\end{array}$ & $\begin{array}{l}\text { Age } \leq 34 \\
n=55,353\end{array}$ & $\begin{array}{l}\text { RR } \\
(95 \% \mathrm{CI})\end{array}$ & $\begin{array}{l}\text { aOR } \\
(95 \% \mathrm{CI})\end{array}$ & $p$ Value \\
\hline $\begin{array}{l}\text { One or more major anomalies } \\
(n=1,804)\end{array}$ & $1.7 \%$ & $2.6 \%$ & $\begin{array}{l}0.66 \\
(0.59-0.74)\end{array}$ & $\begin{array}{l}0.59^{\mathrm{a}} \\
(0.52-0.66)\end{array}$ & $<0.001$ \\
\hline $\begin{array}{l}\text { CNS } \\
(n=496)\end{array}$ & $0.4 \%$ & $0.7 \%$ & $\begin{array}{l}0.55 \\
(0.43-0.6)\end{array}$ & $\begin{array}{l}0.49^{\mathrm{a}} \\
(0.38-0.62)\end{array}$ & $<0.001$ \\
\hline $\begin{array}{l}\text { Renal } \\
(n=226)\end{array}$ & $0.2 \%$ & $0.3 \%$ & $\begin{array}{l}0.66 \\
(0.48-0.92)\end{array}$ & $\begin{array}{l}0.58^{\mathrm{b}} \\
(0.41-0.81)\end{array}$ & 0.002 \\
\hline $\begin{array}{l}\text { Abdominal wall } \\
(n=189)\end{array}$ & $0.1 \%$ & $0.3 \%$ & $\begin{array}{l}0.21 \\
(0.12-0.37)\end{array}$ & $\begin{array}{l}0.23^{c} \\
(0.13-0.40)\end{array}$ & $<0.001$ \\
\hline $\begin{array}{l}\text { Cardiac } \\
(n=302)\end{array}$ & $0.4 \%$ & $0.4 \%$ & $\begin{array}{l}0.92 \\
(0.72-1.20)\end{array}$ & $\begin{array}{l}0.89^{d} \\
(0.68-1.18)\end{array}$ & 0.56 \\
\hline $\begin{array}{l}\text { Thoracic } \\
(n=103)\end{array}$ & $0.09 \%$ & $0.15 \%$ & $\begin{array}{l}0.60 \\
(0.36-0.98)\end{array}$ & $\begin{array}{l}0.56^{\mathrm{e}} \\
(0.34-0.93)\end{array}$ & 0.04 \\
\hline $\begin{array}{l}\text { Head/neck } \\
(n=122)\end{array}$ & $0.15 \%$ & $0.16 \%$ & $\begin{array}{l}0.91 \\
(0.60-1.36)\end{array}$ & - & 0.64 \\
\hline $\begin{array}{l}\text { Gastrointestinal } \\
(n=39)\end{array}$ & $0.03 \%$ & $0.06 \%$ & $\begin{array}{l}0.58 \\
(0.26-1.32)\end{array}$ & - & 0.19 \\
\hline $\begin{array}{l}\text { Musculoskeletal } \\
(n=131)\end{array}$ & $0.13 \%$ & $0.19 \%$ & $\begin{array}{l}0.91 \\
(0.60-1.36)\end{array}$ & - & 0.64 \\
\hline
\end{tabular}

Abbreviations: AMA, advanced maternal age; aOR, adjusted odds ratio; $\mathrm{Cl}$, confidence interval; $\mathrm{CNS}$, central nervous system; RR, relative risk.

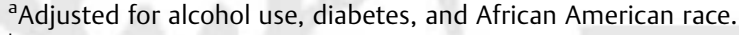

${ }^{\mathrm{b}}$ Adjusted for diabetes and African American race.

${ }^{\mathrm{C}}$ Adjusted for tobacco use, parity, and African American race.

${ }^{\mathrm{d}}$ Adjusted for diabetes, African American race, and body mass index.

${ }^{\mathrm{e}}$ Adjusted for African American race.

Table 3 Subgroup analysis of the association between AMA $\geq 40$ y and major congenital anomalies by organ system

\begin{tabular}{|c|c|c|c|c|c|}
\hline Variable & $\begin{array}{l}\text { AMA } \geq 40 \\
n=4,065\end{array}$ & $\begin{array}{l}\text { Age } \leq 39 \\
n=72,091\end{array}$ & $\begin{array}{l}\text { RR } \\
(95 \% \mathrm{Cl})\end{array}$ & $\begin{array}{l}\text { aOR } \\
(95 \% \mathrm{Cl})\end{array}$ & $p$ Value \\
\hline $\begin{array}{l}\text { One or more major anomalies } \\
(n=1,804)\end{array}$ & $1.8 \%$ & $2.4 \%$ & $\begin{array}{l}0.73 \\
(0.58-0.93)\end{array}$ & $\begin{array}{l}0.70^{\mathrm{a}} \\
(0.54-0.90)\end{array}$ & 0.02 \\
\hline $\begin{array}{l}\text { CNS } \\
(n=496)\end{array}$ & $0.3 \%$ & $0.7 \%$ & $\begin{array}{l}0.51 \\
(0.30-0.67)\end{array}$ & $\begin{array}{l}0.49^{\mathrm{b}} \\
(0.29-0.84)\end{array}$ & 0.01 \\
\hline $\begin{array}{l}\text { Renal } \\
(n=226)\end{array}$ & $0.05 \%$ & $0.31 \%$ & $\begin{array}{l}0.16 \\
(0.04-0.64)\end{array}$ & - & 0.003 \\
\hline $\begin{array}{l}\text { Abdominal wall } \\
(n=189)\end{array}$ & $0.12 \%$ & $0.26 \%$ & $\begin{array}{l}0.48 \\
(0.20-1.17)\end{array}$ & - & 0.09 \\
\hline $\begin{array}{l}\text { Cardiac } \\
(n=302)\end{array}$ & $0.6 \%$ & $0.4 \%$ & $\begin{array}{l}1.67 \\
(1.12-2.49)\end{array}$ & $\begin{array}{l}1.55^{c} \\
(1.00-2.42)\end{array}$ & 0.05 \\
\hline $\begin{array}{l}\text { Thoracic } \\
(n=103)\end{array}$ & $0.17 \%$ & $0.13 \%$ & $\begin{array}{l}1.29 \\
(0.60-2.78)\end{array}$ & - & 0.51 \\
\hline $\begin{array}{l}\text { Head/neck } \\
(n=122)\end{array}$ & $0.12 \%$ & $0.16 \%$ & $\begin{array}{l}0.76 \\
(0.30-1.85)\end{array}$ & - & 0.54 \\
\hline $\begin{array}{l}\text { Gastrointestinal } \\
(n=39)\end{array}$ & $0.05 \%$ & $0.05 \%$ & $\begin{array}{l}0.96 \\
(0.23-3.97)\end{array}$ & - & 0.95 \\
\hline $\begin{array}{l}\text { Musculoskeletal } \\
(n=131)\end{array}$ & $0.12 \%$ & $0.17 \%$ & $\begin{array}{l}0.70 \\
(0.29-1.72)\end{array}$ & - & 0.44 \\
\hline
\end{tabular}

Abbreviations: AMA, advanced maternal age; aOR, adjusted odds ratio; $\mathrm{Cl}$, confidence interval; $\mathrm{CNS}$, central nervous system; RR, relative risk.

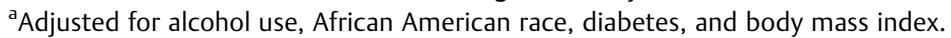

${ }^{b}$ Adjusted for diabetes, alcohol use, and African American race.

'Adjusted for diabetes, African American race, and body mass index. 
risk of major anomalies by 5-year age increments, the authors demonstrated that women older than age 25 had a significantly and progressively greater risk of having a fetus with a nonchromosomal malformation compared with the reference group of women ages 20 to 24 years. Specifically, women older than 25 years had an increased risk for cardiac defects, clubfoot, and diaphragmatic hernia, with this risk most pronounced in women $\geq$ age $40 .^{7}$ Despite the large number of patients included in this study, the absolute number of individual anomalies was low, resulting in wide CIs around the estimated ORs. Similar results were obtained in a secondary analysis of the FASTER (first and second trimester evaluation of risk) trial in which an increased risk of congenital anomalies was observed in women aged 35 to 39 (aOR: 1.4, 95\% CI: 1.11.8 ) and women $\geq 40$ (aOR: $1.7,95 \% \mathrm{CI}: 1.2-2.4$ ). That study, however, did not differentiate between congenital anomalies associated with aneuploidy and isolated anomalies. ${ }^{2}$

In contrast, Baird et al performed a population-based analysis using birth certificate data from 576,815 consecutive livebirths to evaluate the effect of maternal age on the incidence of nonchromosomal congenital anomalies. These authors demonstrated no increase in congenital anomalies with advancing maternal age. ${ }^{8}$ Furthermore, a Swedish birth registry study of nearly 574,000 livebirths and stillbirths reported no increase in the incidence of fetal cardiac defects with advancing maternal age after excluding chromosomal abnormalities, consistent with results from our study. ${ }^{17}$ Also consistent with our findings, Materna-Kiryluk et al demonstrated a decreased risk for neural tube defects with advancing maternal age. ${ }^{9}$

Multiple biological mechanisms have been proposed to support both an increased and decreased risk for major congenital anomalies with advancing maternal age. Mechanisms favoring an increased risk include the increased incidence of aneuploidy with advancing age, accumulation of environmental exposures over time, and the increasing risk of medical comorbidities, such as diabetes, over the course of childbearing years. Conversely, increasing prenatal vitamin use, decreasing substance abuse, and earlier prenatal care have been observed in women of advanced maternal age and may explain the potential decreased risk of congenital anomalies in these women. In addition to these mechanisms, we propose a novel hypothesis suggesting that the "all or nothing" phenomenon, a concept in which early embryonic exposure before organogenesis either results in embryonic death or no adverse outcome, may play a more robust role in development with advancing oocyte age, with anatomically normal fetuses being more likely to survive. Future research to test this hypothesis in vitro may be warranted.

The strengths of our study include our large cohort established by our robust ultrasound and perinatal database which is maintained by a dedicated nurse outcome coordinator. Given this expansive database, we were able to perform a rigorous epidemiologic evaluation, capturing maternal characteristics, ultrasound findings, and pregnancy comorbidities and allowing for adjusted analysis to control for potential confounders which may independently be associated with an increased risk for congenital anomalies. Despite these large numbers, we still were unable to evaluate individual congenital anomalies given their overall rarity; however, we were able to evaluate anomalies by organ system. Most importantly, by selecting our primary outcome as the diagnosis of major fetal anomalies at the time of the second trimester anatomic survey, we not only captured live birth data, but also data for impending stillbirths and terminations, which anecdotally are more likely to be anomalous. Using our well-established follow-up system for pregnancy and neonatal outcome extraction, sonographically suspected major anomalies were able to be confirmed in the postnatal period. In addition, data on anomalies not detected by ultrasound could also be collected.

Our study is not without limitations, including its retrospective design with its potential for misclassification bias and the effect of unknown confounders; however, the nature of this research does not allow for the gold standard randomized controlled trial design. In addition, our perinatal database neither captures information on paternal age, which has been associated with an increased risk for autosomal dominant disorders and their associated anomalies, nor information on the effect of assisted reproductive technology and donor oocytes. Although our study was able to exclude chromosomal abnormalities based on standard karyotype results, we were unable to account for chromosomal deletion/duplication abnormalities assessed by chromosomal microarray analysis, as this is a relatively new technology to be incorporated into our practice. Finally, our population primarily represents a highrisk referral population; however, the proportion of AMA patients evaluated at our center is comparable to the national average. Furthermore, a high-risk referral population would likely have a higher incidence of fetal anomalies, thereby biasing our results in the opposite direction, producing an underestimation of the true association found.

In conclusion, AMA is associated with an overall decreased risk for major congenital malformations in the absence of aneuploidy, specifically driven by a decrease in CNS, renal, and abdominal wall defects. In the era of noninvasive prenatal testing, women are being informed of their aneuploidy risk as early as 10 weeks gestation, months before the time of routine second-trimester anatomic survey. Findings from our study may be used to provide reassurance to these patients during this time of anticipation and may also be incorporated into patient counseling as more women are considering pregnancy at advancing maternal ages.

Note

This article was presented, in part, as an oral presentation at the 34th Annual Meeting of the Society for MaternalFetal Medicine; February 6, 2014; New Orleans, LA.

Conflict of Interest

None.

\section{References}

1 Martin JA, Hamilton BE, Osterman MJK, Curtin SC, Matthews TJ. Births: final data for 2012. Natl Vital Stat Rep 2013;62(9):1-68 
2 Cleary-Goldman J, Malone FD, Vidaver J, et al; FASTER Consortium. Impact of maternal age on obstetric outcome. Obstet Gynecol 2005;105(5 Pt 1):983-990

3 Laopaiboon M, Lumbiganon P, Intarut N, et al; WHO Multicountry Survey on Maternal Newborn Health Research Network. Advanced maternal age and pregnancy outcomes: a multicountry assessment. BJOG 2014;121(Suppl 1):49-56

4 Salem Yaniv S, Levy A, Wiznitzer A, Holcberg G, Mazor M, Sheiner E. A significant linear association exists between advanced maternal age and adverse perinatal outcome. Arch Gynecol Obstet 2011; 283(4):755-759

5 Jacobsson B, Ladfors L, Milsom I. Advanced maternal age and adverse perinatal outcome. Obstet Gynecol 2004;104(4): 727-733

6 Stillbirth Collaborative Research Network Writing Group. Association between stillbirth and risk factors known at pregnancy confirmation. JAMA 2011;306(22):2469-2479

7 Hollier LM, Leveno KJ, Kelly MA, MCIntire DD, Cunningham FG. Maternal age and malformations in singleton births. Obstet Gynecol 2000;96(5 Pt 1):701-706

8 Baird PA, Sadovnick AD, Yee IM. Maternal age and birth defects: a population study. Lancet 1991;337(8740):527-530

9 Materna-Kiryluk A, Wiśniewska K, Badura-Stronka M, et al. Parental age as a risk factor for isolated congenital malformations in a Polish population. Paediatr Perinat Epidemiol 2009;23(1): $29-40$
10 Reefhuis J, Honein MA. Maternal age and non-chromosomal birth defects, Atlanta-1968-2000: teenager or thirty-something, who is at risk? Birth Defects Res A Clin Mol Teratol 2004;70(9):572-579

11 Bille C, Skytthe A, Vach W, et al. Parent's age and the risk of oral clefts. Epidemiology 2005;16(3):311-316

12 Gill SK, Broussard C, Devine O, Green RF, Rasmussen SA, Reefhuis J; National Birth Defects Prevention Study. Association between maternal age and birth defects of unknown etiology: United States, 1997-2007. Birth Defects Res A Clin Mol Teratol 2012; 94(12):1010-1018 (Part A)

13 Csermely G, Czeizel AE, Veszprémi B. Distribution of maternal age and birth order groups in cases with unclassified multiple congenital abnormalities according to the number of component abnormalities: a national population-based case-control study. Birth Defects Res A Clin Mol Teratol 2015;103(2):67-75

14 Csermely G, Susánszky E, Czeizel AE. Association of young and advanced age of pregnant women with the risk of isolated congenital abnormalities in Hungary - a population-based case-matched control study. J Matern Fetal Neonatal Med 2015;28(4):436-442

15 ACOG Committee on Practice Bulletins. ACOG Practice Bulletin No. 77: screening for fetal chromosomal abnormalities. Obstet Gynecol 2007;109(1):217-227

16 Callen PW. Ultrasonography in Obstetrics and Gynecology. Philadelphia, PA: Saunders Elsevier; 2008

17 Pradat P. Epidemiology of major congenital heart defects in Sweden, 1981-1986. J Epidemiol Community Health 1992;46(3):211-215 